\title{
Production of Biaxial Polarization-Maintaining Optical Fiber with Panda-Type and Elliptical-Core Geometry
}

\author{
Ali Karatutlu ${ }^{1}$, Elif Yapar Yıldırım ${ }^{1}$, Esra Kendir ${ }^{1}$, Bülend Ortaç ${ }^{1}$ \\ 1. Bilkent University UNAM-Institute of Materials Science and Nanotechnology, Ankara, 06800, TURKEY
}

Polarization Maintaining (PM) fibers can be produced in different ways in terms of their stress-birefringent geometric structures such as Panda-type, bow-tie and elliptical core [1]. These designs in principal function in the same way causing internal stress on the core and creating birefringence between two orthogonal (slow and fast) axes. In the typical Panda-type PM fibers, polarization extinction ratio (PER) is preserved over $30 \mathrm{~dB}$ along the slow axis and there is over $\sim 10 \mathrm{~dB}$ difference between the fast and slow axes (Region 1 and Region 2, respectively, Fig.1.b.). On the other hand, elliptical core PM fibers can be produced without boron-doped stress rods and thus they are easier to manufacture than the other two PM fibers with compatible birefringence values. Some of the applications require utilizing PM fiber components in order to developed environmentally-stable laser systems [2,3]. For these reasons, a specialty PM fiber structure may be needed in which the properties of both Panda-type and elliptical core geometry PM fibers can be used together.

(a)

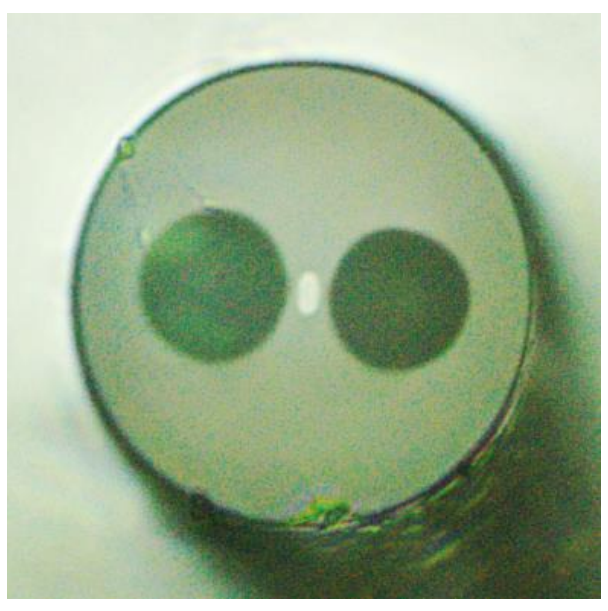

(b)

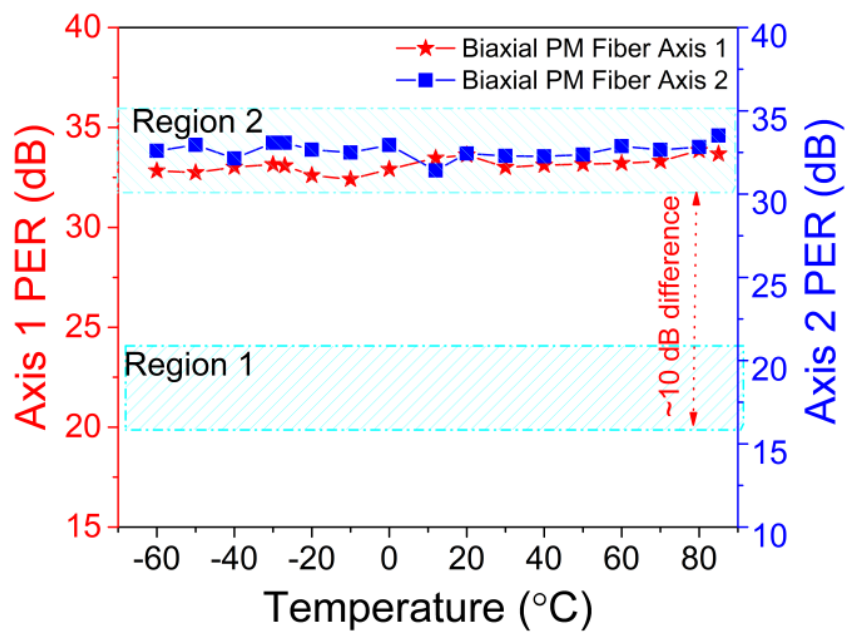

Fig. 1.a. The novel biaxial PM fiber cross-section and b. The evolution of PERs of the biaxial PM fiber at different temperatures from $-60{ }^{\circ} \mathrm{C}$ to $+85^{\circ} \mathrm{C}$.

In this study, we fabricated a biaxial PM fiber both with the stress-applying parts and an elliptical core (Fig.1.a.) by carefully controlling the fabrication parameters to increase the internal stress on the core region leading to formation of such fiber core structure. The biaxial PM fiber demonstrates that the PERs are maintained along two-main axes over $30 \mathrm{~dB}$ (Fig. 1.b.) between the operation temperatures from $-60{ }^{\circ} \mathrm{C}$ to +85 ${ }^{\circ} \mathrm{C}$. This result yields an improvement of over $10 \mathrm{~dB}$ with respect to the fast axis of Panda-type fiber in which the PM property is limited. These high PER values along two axes within the operational temperatures show a huge potential of the biaxial PM fiber in the high precision fiber-optic gyroscopes.

\section{References}

1. C. Emslie, "Polarization Maintaining Fibers," in Specialty Optical Fibers Handbook (Elsevier, 2007), pp. $243-277$.

2. T. Schreiber, C. K. Nielsen, B. Ortac, J. Limpert, and A. Tünnermann, "Microjoule-level all-polarization-maintaining femtosecond fiber source," Opt. Lett. 31, 574 (2006).

3. C. K. Nielsen, B. Ortaç, T. Schreiber, J. Limpert, R. Hohmuth, W. Richter, and A. Tünnermann, "Self-starting self-similar allpolarization maintaining Yb-doped fiber laser," Opt. Express 13, 9346 (2005). 